\title{
Experimental Thermal evaluation of Fluidized Bed Cooling Tower (FBCT) with various Bed elevations and Spherical turbulent balls
}

\author{
N.Mukilarasan ${ }^{* 12}$, R.Karthikeyan ${ }^{3}$ \\ ${ }^{*}$ Research scholar, Department of Mechanical Engineering, Annamalai University, Chidambaram, \\ Tamilnadu,India. \\ ${ }^{2}$ Department of Mechanical Engineering, Jeppiaar institute of Technology, Chennai TN, India. \\ ${ }^{3}$ Department of Mechanical Engineering, Annamalai University, Chidambaram, Tamilnadu, India. \\ *Email:mukil09tea19@gmail.com
}

\begin{abstract}
An investigation was carried out to determine the thermal performance of FBCT. The analysis was conducted with different bed heights of $30 \mathrm{~cm}$ and $20 \mathrm{~cm}$ with different ball diameters of $2.5 \mathrm{~cm}$ and $5 \mathrm{~cm}$. The tower characteristics were evaluated with air-side pressure drop and lowest fluidization velocity. The investigational outcomes presented that thermal performance of tower improved for higher bed height. The higher velocity is achieved by using $25 \mathrm{~mm}$ spherical turbulent balls than $50 \mathrm{~mm}$ balls due to the effective air mixing at the entry. In the case of fluidized bed of $30 \mathrm{~cm}$ height with water flow rate of $2 \mathrm{lpm}$ and ball diameter of $5 \mathrm{~cm}$, the cooling tower efficiency was determined as $61.81 \%, 68.01 \%, 69.88 \%$, $72.59 \%$ and $76.99 \%$ at the air flow rates of $4.1 \mathrm{~m} / \mathrm{s}, 6.3 \mathrm{~m} / \mathrm{s}$, $7.0 \mathrm{~m} / \mathrm{s}, 8.2 \mathrm{~m} / \mathrm{s}$ and $8.5 \mathrm{~m} / \mathrm{s}$ correspondingly. The cooling tower efficiency for $\mathrm{BH} 30 \mathrm{~cm}$ and $\mathrm{BD} 2.5 \mathrm{~cm}$ with water flow rate of $2 \mathrm{lpm}$, was found to be $78.94 \%, 86.36 \%, 91.85 \%$, $90.14 \%$ and $92.83 \%$.Two effective regimes were established at the interaction between air and water such as pellicular (PR) and a bubble and dispersion regimes (BDR). The better heat transfer is determined by these two regimes only. The BDR regime promotes better heat transfer than pellicular regime which enables larger cooling performance for given water flow rates.
\end{abstract}

Key words : Fluidized Bed Cooling tower, Bed height, Fluidized ball, L/G ratio, Cooling tower efficiency, Evaporative loss.

\section{INTRODUCTION}

Excess heat energy must be continuously removed from the process industries, manufacturing plants and power generating systems to operate efficiently. A cooling tower is a heat rejection device that removes surplus heat energy from the operative elements and exhausted into the environment. The cooling tower works on the evaporative cooling method that permits a small volume of the water to be cooled for evaporation into a flowing air stream. For better cooling application, the cooling towers are generally used to give lesser water temperatures than other cooling systems such as air cooled or dry heat rejection systems. It is most cost effective and better energy efficient when compared to other cooling systems. Vishwanath et al.[1] have investigated thermal performance of FBCT for different flow rates. The outcomes presented an enhancement in the cooling performance of the tower with a rise in $\mathrm{L} / \mathrm{G}$ ratio without any fluctuations for different inlet temperatures $\left(60^{\circ} \mathrm{C}, 55^{\circ} \mathrm{C}\right.$, $50^{\circ} \mathrm{C}$ ). Also, FBCT had very lesser drift losses than without the bed. The reason was that the air from the blower can contact with the fluidized bed materials in which the pressure of the air in the bed got reduced. Seetharamu et al. [2] have performed in FBCT using bed materials of different structures. The results revealed that the shape of the packing materials played a vital role in terms of performance of FBCT (Fluidized Bed Cooling Tower) and also the best configuration was not achieved by using spherical shape. Boumaza et al [3] have studied the performance of a counter flow wet cooling tower. The tower is made up of VGA (Vertical Grid Apparatus) with 0.42 high and four galvanized sheets of zigzag form. The higher thermal effectiveness is observed during the Pellicular regime whereas, the higher amount of water flow rates obtained with the Bubble and Dispersion Regime (BDR).

Gao et al. [4] have studied drag and thermal characteristics of wet cooling towers with crosswind conditions. The experimental results showed that $\mathrm{P} 4$ pattern was the optimal non-uniform patter under crosswind environments. The P4 pattern provided the higher ventilation rate, heat transfer coefficient, Merkel number and reduced drag coefficient. However, the P3 patter exhibited lower evaporation loss and the considerable water saving performance. Kong et al. [5] examined heat and mass transfer characteristics in a counter flow wet cooling tower using foam ceramic packing materials. The study concluded that the foam type ceramic packing material resulted in better cooling performance of the tower when compared to other packing materials. Chaibi et 
al. [6] have done performance analysis of a mechanical geothermal water cooling tower. The obtained results showed that ambient humidity influenced a major part in the performance of the cooling tower than external temperature. The cooling efficiency (about 80\%) was higher during summer conditions due to high temperature and low humidity of the ambient air. Also, the results indicated that the effective evaporative cooling exhibited better performance than convective cooling system.

Li et al. [7] have optimized in reversibly used cooling tower with downward spraying technique on thermal performance of initial solution temperature, gas velocity, initial droplet velocity, and droplet diameter. The results presented that the thermal performance of packed bed RUCT (75\%) was higher than RUCT related to upward spraying. The packed bed RUCT was severely affected by the fouling problems. The tower effectiveness was achieved up to $99.9 \%$ using optimized DSRUCT method. Hence, the augmented DSRUCT method solved the fouling issues and ensured the better thermal performance. Kalpana et al. [8] have used plastic ball as packing material to determine the performance of FBCT. The tower efficiency increased with the temperature ratio due to the increase of airflow rate with decreased outlet water temperature. At different $\mathrm{L} / \mathrm{G}$ ratios, the NTU increased with higher temperature ratio. The higher airflow rate resulted in higher pressure drop. Finally, the results showed that the cooling rate of $50 \%$ was achieved by this technique than other methods. The higher cooling rates were achieved by lower L/G ratios. Dessouky [9] carried out a thermal and hydraulic performance of a three phase fluidized bed cooling tower. In this analysis, a packed tower of $200 \mathrm{~mm}$ diameter and $2.5 \mathrm{~m}$ height were used. The packing material used was spongy rubber balls with $12.7 \mathrm{~mm}$ in diameter and a density of $375 \mathrm{~kg} / \mathrm{cm}^{3}$. The experimental results indicated that the tower characteristics increased with increased in the static bed height and hot water inlet temperature and decreased for air/water mass flux ratio. It was also observed that the air-side pressure drop increased very slowly with an increase in air velocity. Hamed et al. [10] have investigated theoretically and experimentally on the transient attached heat and mass transfer in a radial flow desiccant packed bed. The system parameters were taken as bed weight, air velocity, DBT, WBT. A hollow cylindrical packed bed was used as a desiccant dehumidifier. The power required to blow the air through the bed was decreased by this configuration. This technique used simple effectiveness correlations for steady state heat and mass exchangers within a finite difference procedure. The influencing parameters for system performance were found out as the initial water content of the bed and its initial temperature. Moreover, the system performance was improved by the bed cooling at adsorption.

The aim of this investigation is to examine the thermal performance characteristics of fluidized bed cooling tower with bed and without bed materials for various water flow rate and air flow rates and different inlet temperature of water flow rates. Also, this paper presents the results of thermal parameters affecting the thermal effectiveness of the FBCT and heat rejection by this tower.

\section{THERMAL CHARACTERISTICS OF FLUIDIZED BED COOLING TOWER}

The performance of FBCT can be measured by cooling tower effectiveness and the heat rejected from the cooling tower.

\subsection{Cooling tower efficiency}

Cooling tower efficiency can be expressed as

$\mu=(\mathrm{t} 1$ - $\mathrm{t} 2) 100 /(\mathrm{t} 1$ - twb) -- ------ (1)

where,$\mu=$ cooling tower efficiency $(\%)$

$\mathrm{t} 1=$ inlet temperature of water to the tower $\left({ }^{\circ} \mathrm{C}\right)$

$\mathrm{t} 2=$ outlet temperature of water from the tower $\left({ }^{\circ} \mathrm{C}\right)$

twb $=$ wet bulb temperature of air $\left({ }^{\circ} \mathrm{C}\right)$

2.2 Number of Transfer Unit (NTU)

$$
\mathrm{NTU}=(\mathrm{Ka} \mathrm{V} / \mathrm{L})=\mathrm{CW} \int_{T_{2}}^{\mathrm{T}^{1}} \mathrm{dT} /(\mathrm{h} 2-\mathrm{h} 1)
$$

\section{3 L/G Ratio}

$$
\mathrm{L} / \mathrm{G}=(\mathrm{h} 2-\mathrm{h} 1) /(\mathrm{T} 1-\mathrm{T} 2)
$$

\subsection{Different losses}

Drift Loss $(\mathrm{DL})=(0.20 \mathrm{Mw}) / 100$

Evaporative Loss $=0.00085 \mathrm{Mw}(\mathrm{T} 1-\mathrm{T} 2)$

Table 1: Cooling tower dimensions

\begin{tabular}{|l|l|}
\hline Parameter & Dimension \\
\hline Duct dimensions & $\begin{array}{l}100 \mathrm{~cm} \text { height and } 20 \mathrm{~cm} \times 20 \mathrm{~cm} \text { cross } \\
\text { section (square) }\end{array}$ \\
\hline Thickness & $0.15 \mathrm{~cm}$ \\
\hline Air Blower & 650 Watts \\
\hline Rotameter & $2-18 \mathrm{lpm}$ \\
\hline $\begin{array}{l}\text { Induction Water } \\
\text { heater }\end{array}$ & 3000 Watts \\
\hline RTD & \\
\hline
\end{tabular}

\section{EXPERIMENTAL SET-UP AND PROCEDURE}

Figure. 1 shows a detailed actual experimental setup and used components to determine the heat and mass transfer characteristics of fluidized bed cooling tower. The duct has height of $100 \mathrm{~cm}$ and $20 \mathrm{~cm} \times 20 \mathrm{~cm}$ cross sectional square [Table 1] area with thickness of $0.15 \mathrm{~cm}$. Rotameter was used to supply the cooling water with discharge capacity of 2.18 $\mathrm{lpm}$. Water was uniformly distributed throughout the cooling tower. A water tank was kept at the bottommost of the tower to collect the cooled water from the tower. A water pump was used to supply the water from the reservoir to the top of the tower column. U-tube manometer was used to measure the pressure drop across the air flow passages. The various temperatures were measured by RTD sensors. The induction water heater was used to supply the heat energy with capacity of 3000 watts. The fluidized air was supplied to the tower using a centrifugal air blower with a capacity of 650 watts. A control valve was used to control the air flow rate to the column. Moreover, a bypass circuit was attached before the throttle valve to avoid any damage to the air blower. The inlet 
air temperature was controlled by an electrical air heater. Figure.2 displays the line diagram of the investigational system [9].

The experiments were repeated for the following parameters

1. The variation in the air velocity

2. The variation in the water velocity

3. The variation of Bed height $(20 \mathrm{~cm}$ and $30 \mathrm{~cm})$

4. The variation in Fluidized Ball diameter $(25 \mathrm{~mm}$ and $50 \mathrm{~mm}$ spherical balls)

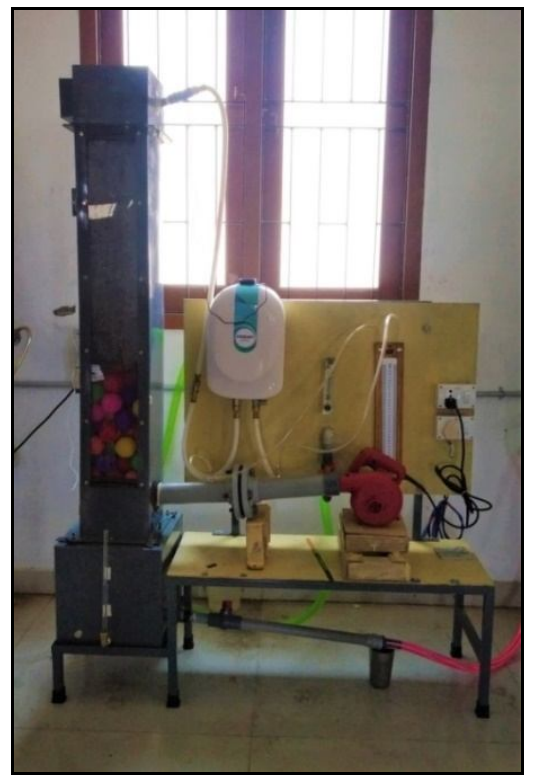

Figure1: Actual photograph of Fluidized Bed Cooling tower

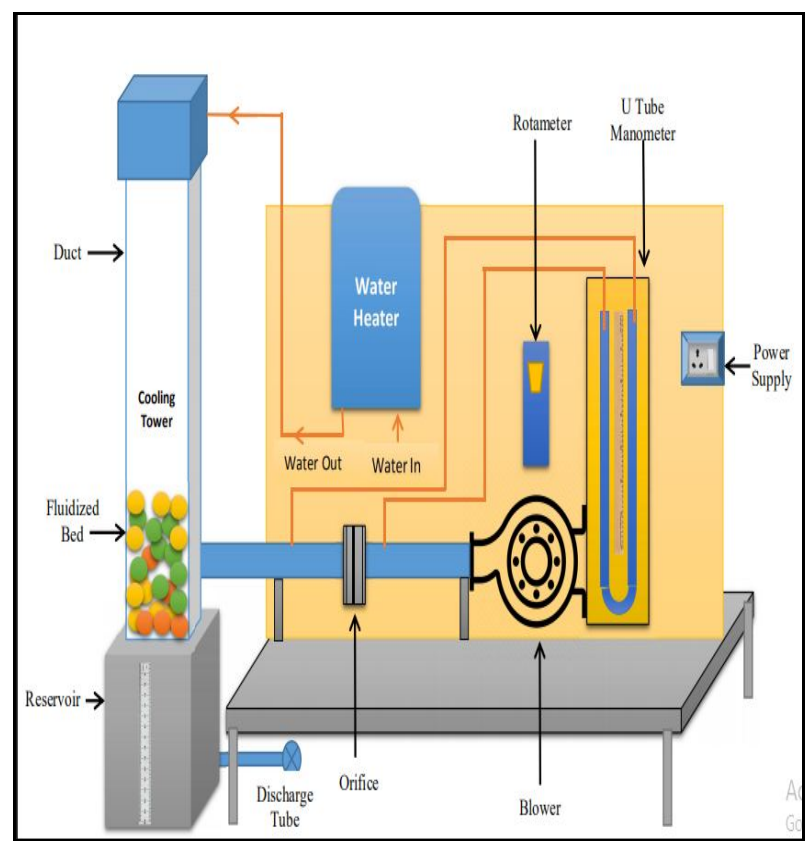

Figure 2: Schematic diagram of experimental set-up

\section{RESULTS AND DISCUSSION}

The characteristics of a cooling tower are primarily influenced by the range and the approach of the cold water,
L/G ratio. The two important zones were determined through the contact between air and water in the cooling tower. The first zone is called as pellicular regime (PR) which occurs at lower water flow rates. Another regime is known as bubble and dispersion regime (BDR) which happens with comparatively higher flow rates.

\subsection{Air velocity Vs Cooling tower efficiency}

Figure.3 demonstrates the difference of cooling tower efficiency with respect to different air velocities. The cooling tower efficiency increased for $\mathrm{BH} 30 \mathrm{~cm}$ with $\mathrm{BD} 5 \mathrm{~cm}$ than other cases. One can observe that the lowest temperature to which the cooled water is the WBT of the atmospheric air. The cooling tower efficiency for BH $30 \mathrm{~cm}$ and BD $2.5 \mathrm{~cm}$ with water flow rate of $2 \mathrm{lpm}$, was found to be $78.94 \%, 86.36 \%$, $91.85 \%, 90.14 \%$ and $92.83 \%$ at the air flow rates of $4.1 \mathrm{~m} / \mathrm{s}$, $6.3 \mathrm{~m} / \mathrm{s}, 7.0 \mathrm{~m} / \mathrm{s}, 8.2 \mathrm{~m} / \mathrm{s}$ and $8.5 \mathrm{~m} / \mathrm{s}$ respectively.

But in the case of conventional cooling towers, it is not possible to cool the water up to the WBT. The reason is that all the water could not able to contact with fresh air as the water flows through the fill surfaces [10-12]

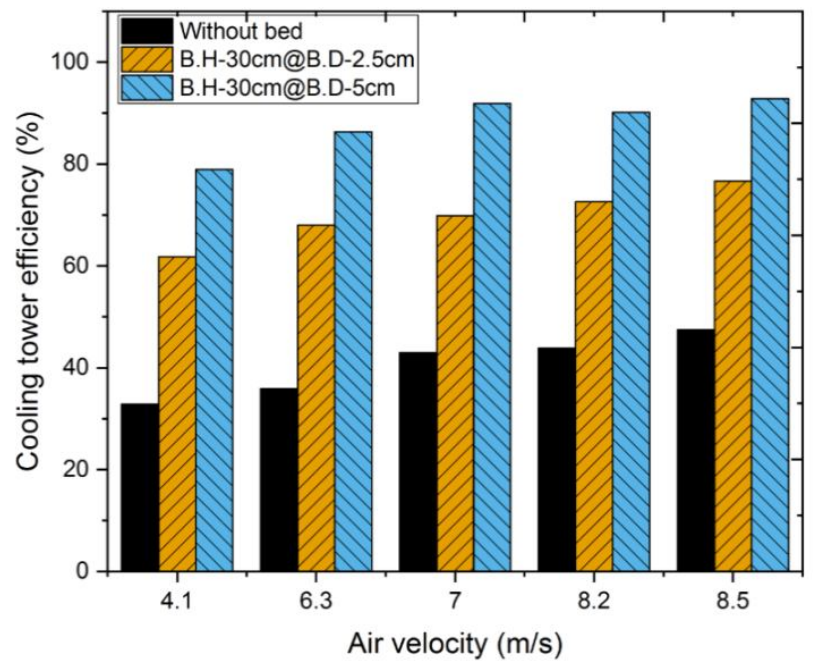

Figure 3: Cooling tower efficiency Vs Air velocity

\subsection{Air velocity Vs Evaporative loss}

Figure. 4 indicates the variance of the evaporative loss with different air velocities. The evaporative loss is higher for $\mathrm{BH} 30 \mathrm{~cm}$ with $\mathrm{BD} 5 \mathrm{~cm}$ when compared to other cases. For cooling tower packing, the water flow is mainly affected by the gravity, and the air flow with natural convection. The evaporative cooling was observed by latent heat of evaporation influenced by the water evaporation process [13-15]. 


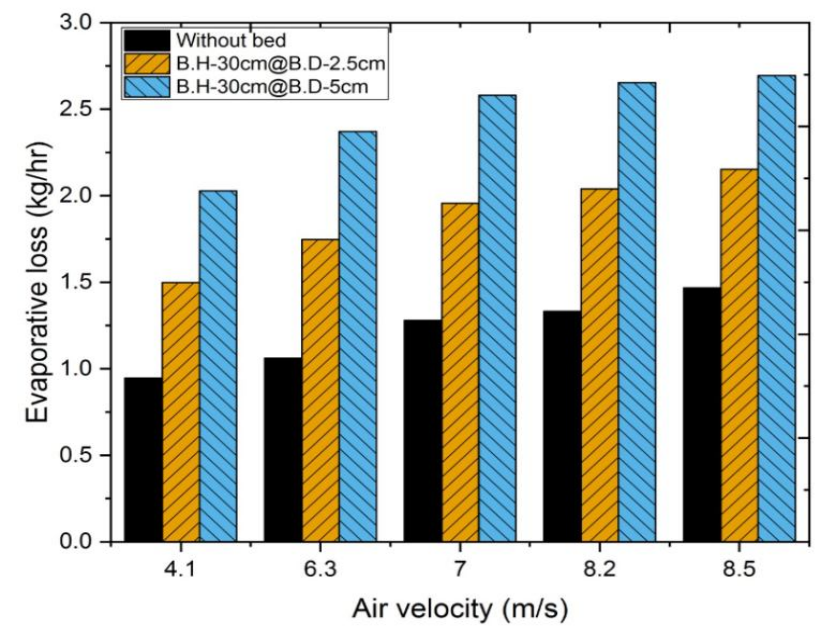

Figure 4: Evaporative loss Vs Air velocity

\subsection{Air velocity vs L/G}

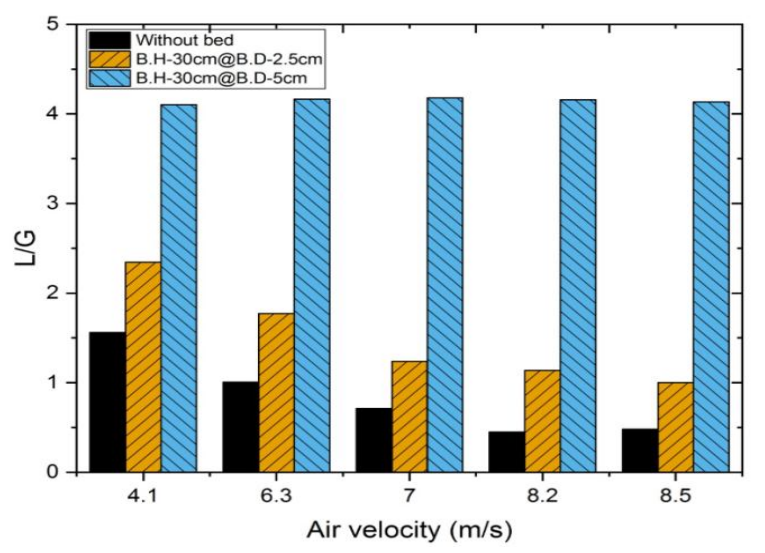

Figure 5: L/G vs Air velocity

Figure. 5 shows the variation of $\mathrm{L} / \mathrm{G}$ ratio for various air velocities. The highest $\mathrm{L} / \mathrm{G}$ ratio was observed for $\mathrm{BH} 30 \mathrm{~cm}$ with $\mathrm{BD} 5 \mathrm{~cm}$. from the graph, it is observed that $\mathrm{L} / \mathrm{G}$ ratio increased rapidly and then decreased, after some period the curve showed a constant value. It is mainly influenced by the temperature and enthalpy. At higher temperatures, the L/G ratio becomes almost constant [16-17].

\subsection{Air velocity Vs NTU}

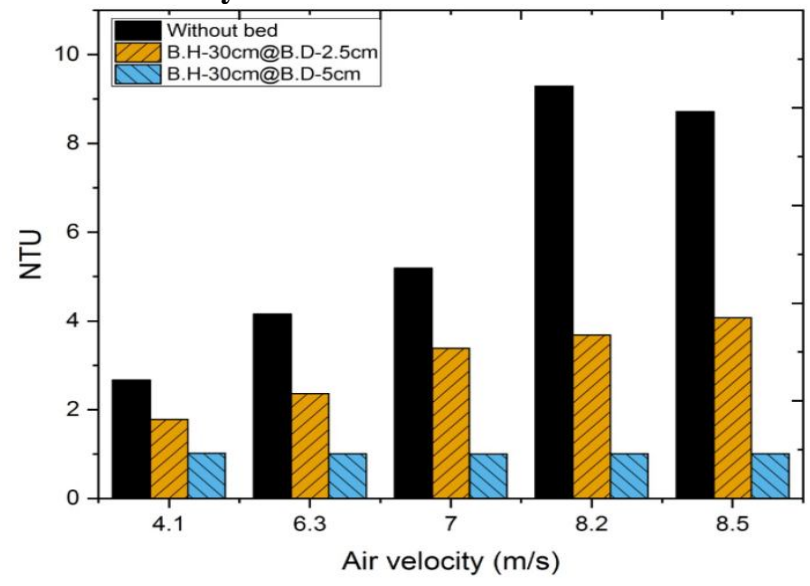

Figure 6 :NTU Vs Air velocity
Figure.6 shows the variation of NTU with different air velocities. The lowest NTU is observed for $\mathrm{BH} 30 \mathrm{~cm}$ with $\mathrm{BD} 5 \mathrm{~cm}$ than other types. The rate of increase of water temperature is very small with $\mathrm{L} / \mathrm{G}$ ratio. A sharp growth of the slope of the curve is witnessed when the $L / G$ ratio is increased. It is credited to the lower segment of water evaporation per unit of entry water. It is due to the improved liquid flow rate which raises the liquid stickup that results in development of bed. At higher L/G ratio, the cooling tower characteristics are decreased [18,21].

\subsection{Water flow rate Vs Cooling tower efficiency}

The cooling tower efficiency is generally given in terms of heat transfer efficiency that will determine the amount of evaporative cooling. Figure.7 shows the variation of cooling tower efficiency with different water flow rates. The heat transfer performance was measured by the ratio of actual to maximum water temperature decrease. The cooling tower efficiency increased with a rise for all the water flow rates. The maximum cooling tower efficiency was observed at bed height of $30 \mathrm{~cm}$ with ball diameter of $5 \mathrm{~cm}$. The cooling tower efficiency without the bed material was found as $31.4 \%$, $36.5 \%, 43 \%, 43.4 \%$ and $47.4 \%$ for the various air flow rates. In the case of fluidized bed of $30 \mathrm{~cm}$ with water flow rate of 2 lpm and ball diameter of $5 \mathrm{~cm}$, the cooling tower efficiency was found to be $61.81 \%, 68.01 \%, 69.88 \%, 72.59 \%$ and $76.99 \%$ for the various air flow rates. The increase in tower efficiency is because of the greater enthalpy potential different between the entry hot and cooled water temperatures [19].

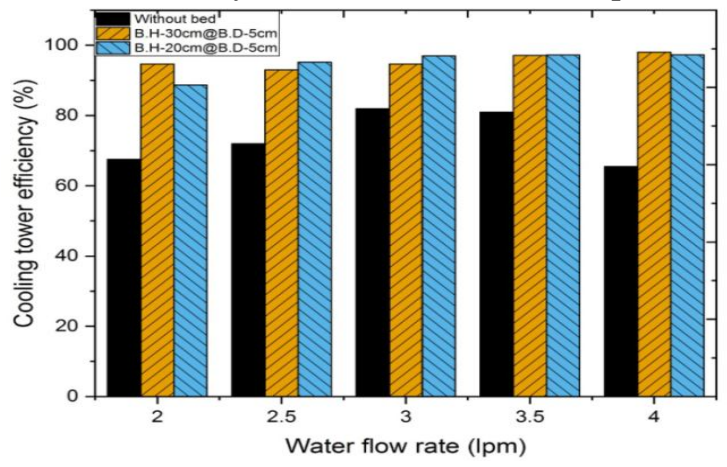

Figure 7 :Cooling tower efficiency Vs Water flow rate

\subsection{Water flow rate Vs Evaporative loss}

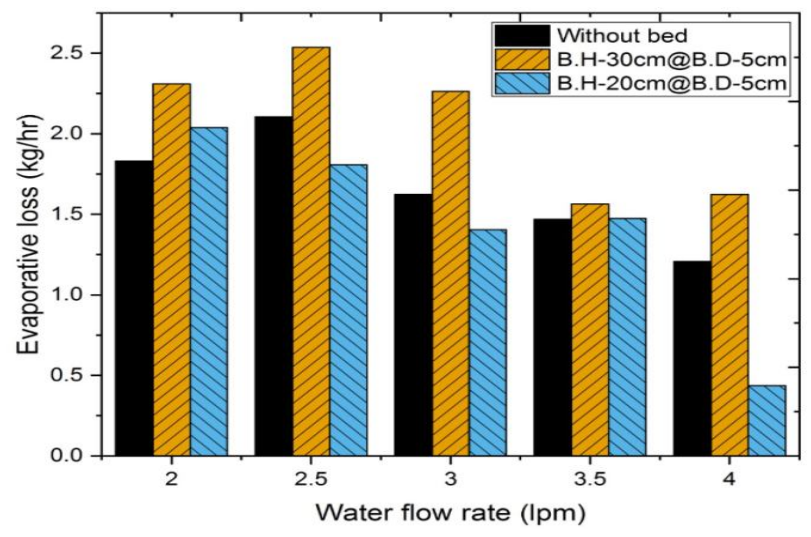

Figure 8: Evaporative loss Vs Water flow rate 
Figure. 8 depicts the variance of evaporative loss based on the various water flow rates. From the figure, it is observed that the evaporative loss was lower for $\mathrm{BH} 20 \mathrm{~cm}$ with $\mathrm{BD} 5 \mathrm{~cm}$. the highest evaporative loss was observed for $\mathrm{BH} 30 \mathrm{~cm}$ with $\mathrm{BD}$ $5 \mathrm{~cm}$. The lowest evaporative exhibited with $\mathrm{BH} 20 \mathrm{~cm}$ and $\mathrm{BD}$ $5 \mathrm{~cm}$. The reason is rise in the evaporation of water per unit mass of entry air stream. The two regimes influenced the water evaporation such as Bubble and Dispersion regime [20, 22].

\subsection{Water flow rate Vs L/G}

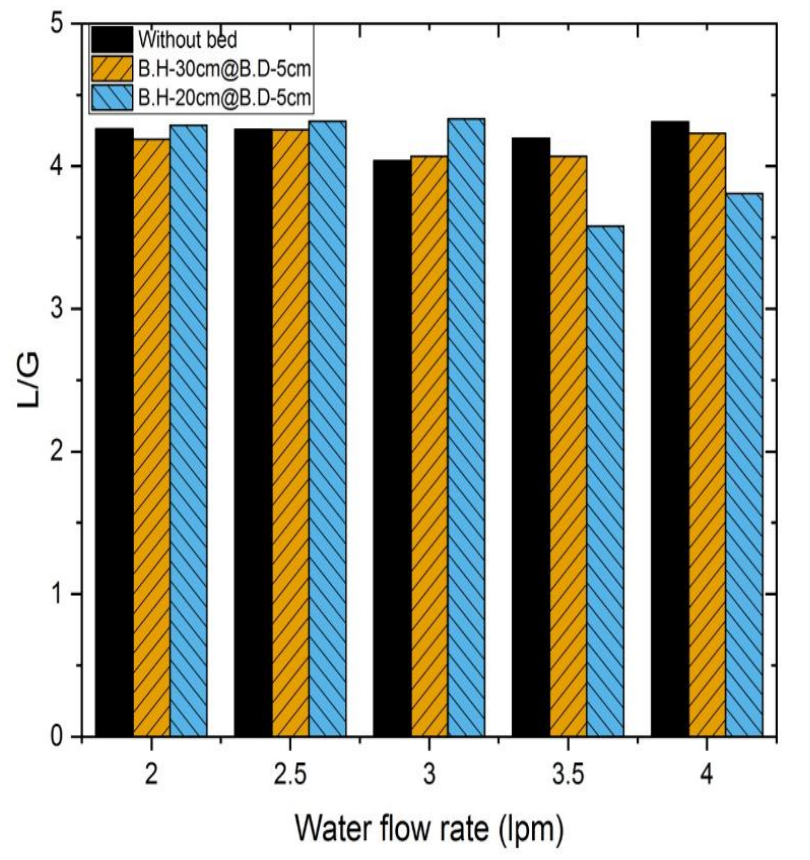

Figure 9: L/G ratio Vs Water flow rate

Figure.9 displays the variance of $L / G$ ratio with respect to different water flow rates. $L / G$ ratio for without bed showed a higher value when compared to with bed. It may be due to the rise in the cooling potential of the tower in which the water flow rate was reduced subsequently with a partial cooling potential during higher water flow. L/G ratio without the fluidized bed and air flow velocity of $8.47 \%$ was found to be $0.5,0.75,1,1.25$ and 1.5 at the water flow rates of $2 \mathrm{lpm}, 2.5$ $\mathrm{lpm}, 3 \mathrm{lpm}, 3.5 \mathrm{lpm}$ and $4 \mathrm{lpm}$ respectively. The infinite cooling cannot be achieved in practical $[15,18]$.

\subsection{Water flow rate Vs NTU}

Figure. 10 shows the variation of NTU for different water flow rates. The highest NTU was observed for with bed height of $20 \mathrm{~cm}$ and ball diameter of $5 \mathrm{~cm}$. when the $\mathrm{L} / \mathrm{G}$ ratio is improved, the mass flux is decreased. The reduction of heat and mass transfer rate was observed at the degree of interfacial activity, which results in a rise in the cold water temperature. Moreover, the fluidized bed becomes unstable when the lower fluidization water velocity was approached. The stable fluidized bed is achieved with a decrease in the mass flux of water, due to the attainment of lower outlet water temperatures $[2,8]$.

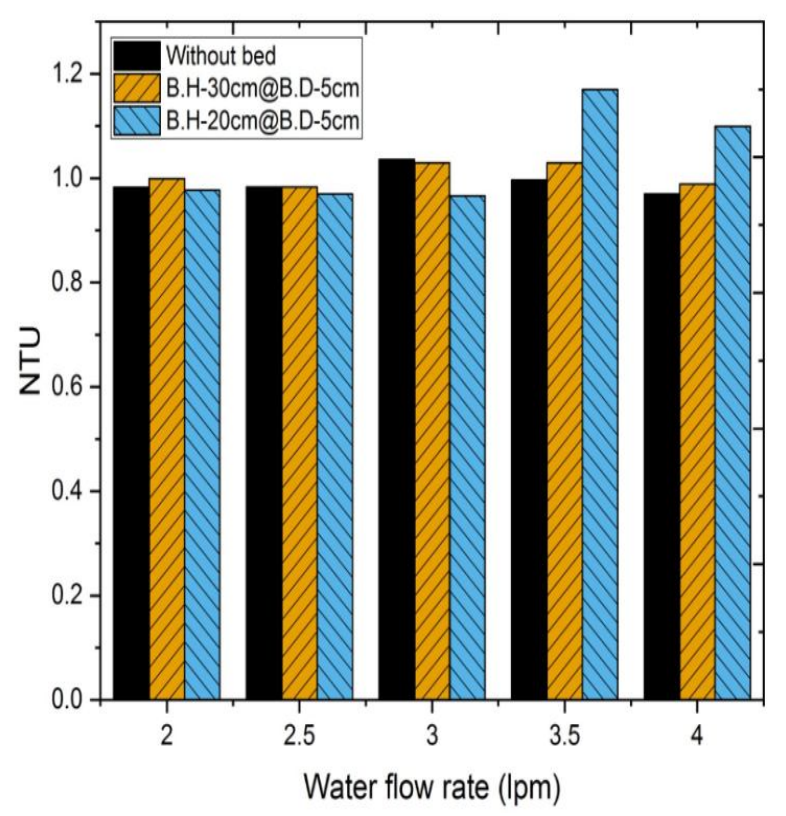

Figure 10: NTU Vs Water flow rate

\section{CONCLUSION}

The following observations are being summarized from the experimental study.

The cooling tower characteristics decreased with rise in water and air mass flux ratio. Static bed height is the one of the influencing parameter for tower characteristics and strongly depends on the higher inlet temperature of water. The lower fluidization velocity was not much related to the static bed height, and then it is based on the water mass flux. Water to air mass flow relation is used for energy analysis. Moreover, the cooling tower's exit water temperature is one the influenced parameter for the energy depletion of a heat element. The cooling tower efficiency for $\mathrm{BH} 30 \mathrm{~cm}$ and $\mathrm{BD}$ $2.5 \mathrm{~cm}$ with water flow rate of $2 \mathrm{lpm}$, was found to be $78.94 \%$, $86.36 \%, 91.85 \%, 90.14 \%$ and $92.83 \%$ at the air flow rates of $4.1 \mathrm{~m} / \mathrm{s}, 6.3 \mathrm{~m} / \mathrm{s}, 7.0 \mathrm{~m} / \mathrm{s}, 8.2 \mathrm{~m} / \mathrm{s}$ and $8.5 \mathrm{~m} / \mathrm{s}$. It is proposed to increase the deviation in air flow and water flow rates for comparatively greater inlet water temperatures and tower heights.

\section{REFERENCES}

1. Vishwanath MM, Experimental investigations for the thermal characteristics of Fluidized Bed Cooling tower at higher flow rates. International Journal of Mechanical and Production Engineering vol 4 (6) (2016) pp 143-149.

2. K.N. Seetharamu and K.V.S. Varier, Performance of a fluidized bed cooling tower using bed materials of various configuration. Warme-und Stoffubertrangung vol 22 (1998) pp 219-222.

https://doi.org/10.1007/BF01052990

3. M. Lemouari, M. Boumaza, I.M. Mujtaba, Thermal Performances investigation of a wet cooling tower. Applied Thermal Engineering vol 27 (2007) pp 902-909. 
4. Yang Zhou, Kun Wang, Min Gao, Zhigang Dang, Suoying He, Fengzhong Sun. Experimental study on the drag characteristics and thermal performance of non-uniform fillings for wet cooling towers under crosswinds conditions. Applied Thermal Engineering 2018 vol.18 pp. 1-21.

5. Qing Jie Kong, Xue Yi Zhao, De QiangXie, Ben Zhang and Pei Wang, Experimental investigation of the heat and mass transfer phenomena in a counter flow wet cooling tower with foam ceramic packing. Advances in Mechanical

Engineering 2018 vol 10 (1) pp 1-11. https://doi.org/10.1177/1687814017752579

6. M.T. Chaibi, K. Bourouni, M.M. Bassem, Experimental Analysis of the performance of a mechanical geothermal water cooling tower in south Tunisia. American Journal of Energy Research, 2013 (1) pp 1-6.

7. Haijiao Cui, Nianping Li, Xinlei Wang, JinqingPeng, Yuan $\mathrm{Li}$, Zhibin $\mathrm{Wu}$, Optimization of reversibly used cooling tower with downward spraying. Energy 127 (2017) pp 30-43.

8. Kalpana. E, Mohanasundaram.T, Performance of Fluidized bed cooling tower, International Journal of Advanced research trends in Engineering and Technology, 3 (2016) pp 1-5.

9. Hisham El-Dessouky, Thermal and Hydraulic performance of a Three-phase Fluidized Bed Cooling Tower, Experimental Thermal and Fluid Science vol 3 (1993) pp 417-426

10. A.M. Hamed, W.R. Abd-Elrahman, S.H. El-Emam, M.M. Awad, Theoritical and experimental investigation on the transient coupled heat and mass transfer in a radial flow desiccant packed bed, Energy Conversion and Management vol 65 (2013) pp 262-271.

11. Justin R. Finn, Janine E. Galvin, Katherine Hornbostel, CFD investigation of $\mathrm{CO} 2$ absorption/desorption by a fludized bed of micro-encapsulated solvents. Chemical Engineering Science:

X6(2020) 100050.

https://doi.org/10.1016/j.cesx.2019.100050

12. Hisham El-Dessouky, Thermal and Hydraulic Performance of a Three-phase Fluidized bed Cooling tower. Experimental Thermal and Fluid Science 1993; 6:pp 417-426.

13. M. Lemouari, M. Boumaza, I.M. Mujtaba, Thermal Performances investigation of a wet cooling tower. Applied Thermal Engineering 27 (2007) pp 902-909.

14. A.M. Hamed, W.R, Abd-Elrahman, S.H. El-Emam, M.M. Awad, Theoritical and experimental investigation on the transient coupled heat and mass transfer in a radial flow desiccant packed bed. Energy Conversion and Management 65 (2013) pp 262-271.

15. Cheng-Qin Ren, Corrections to the simple effectiveness-NTU method for counterflow cooling towers and packed bed liquid desiccant-air contact systems. International Journal of Heat and Mass Transfer 51 (2008) pp 237-245.

16. J.C. Kloppers, D.G. Kroger, A Critical investigation into the head and mass transfer analysis of counterflow wet-cooling towers. International Journal of Heat and Mass Transfer 48 (2005) pp 765-777.

17. HichemMarmouch, JamelOrfi, Sassi Ben Nasrallah, Experimental study of the performance of cooling tower used in a solar distiller. Desalination 250 (2010)pp 456-458.

18. M.S. Soylemez, On the optimum performance of forced draft counter flow cooling towers. Energy Conversion and Management 45 (2004) pp 2335-2341. https://doi.org/10.1016/j.enconman.2003.11.023

19. J. Smrekar, J. Oman, B. Sirok, Improving the efficieincy of natural draft cooling towers. Energy Conversion and $\quad$ Management 47 (2006) pp 1086-1100.

20. Pascal Stabat, Dominique Marchio, Simplified model for indirect-contact evaporative cooling-tower behaviour. Applied Energy 78 (2004) pp 433-451.

21. WanchaiAsvapoositkul, MantheerapolKuansathan, Comparative evaluation of hybrid (dry/wet) cooling tower performance. Applied Thermal Engineering 71 (2014) pp 83-93.

22. M. Lucas, P.J. Martinez, A. Viedma, Experimental study on the thermal performance of a mechanical cooling tower with different drift eliminators. Energy Conversion and Management 50 (2009)pp 490-497.

https://doi.org/10.1016/j.enconman.2008.11.008 